\title{
Previous and Current Crop Effects on Early-Season Root Growth and Growing Season's Soil Moisture Under Dryland Agriculture in Temperate Climate
}

\author{
Kabal S. Gill ${ }^{1} \&$ Surinder K. Jalota ${ }^{2}$ \\ ${ }^{1}$ SARDA Ag Research, Falher, AB, Canada \\ ${ }^{2}$ Punjab Agricultural University, Ludhiana, Punjab, India \\ Correspondence: Kabal S. Gill, SARDA Ag Research, P.O. Box 90, Falher, AB, T0H 1M0, Canada. Tel: \\ 1-780-837-1143. E-mail: consultant@sarda.ca
}

Received: February 12, 2021

Accepted: March 24, $2021 \quad$ Online Published: April 15, 2021

doi:10.5539/jas.v13n5p50

URL: https://doi.org/10.5539/jas.v13n5p50

\begin{abstract}
Understanding the root growth and changes in soil moisture content during the growing season for dryland agriculture crops can improve crop production. It was hypothesized that early-season root growth might be influenced by previous crop and current crops, and soil moisture content and depletion pattern during the growing season and residual soil moisture may be affected by the crop type. A study was conducted on the early-season root growth of canola (Brassica napus L.), wheat (Triticum aestivum L.), and flax (Linum usitatissimum L.) in 2015; and changes in soil water content during the 2013, 2014, and 2015 growing seasons under canola, flax, wheat, barley (Hordeum vulgare L.), and pea (Pisum sativum L.). Early-season root growth of the canola and flax crops was better on wheat than canola stubble, while for wheat it was similar on the stubbles of both wheat and canola. Soil moisture depletion started relatively earlier under the barley and wheat and later under the flax compared to the canola and pea crops. Flax continued to deplete soil moisture for a longer period than the other crops. With some exceptions, all crops could deplete soil moisture to a similar level (down to about $15 \%$ or somewhat lower) by the end of their growing seasons. Generally, almost equal amounts of residual soil moisture remained after the different crops.
\end{abstract}

Keywords: canola, cereals, root length, area, volume, flax, pea, soil moisture

\section{Introduction}

Dryland agriculture is practiced in the study area. The water used by crops comes from rain during the growing season, plus the stored soil moisture from rain/snow before seeding and depletion from the root zone (soil moisture in the soil profile at seeding - harvesting of crops). Under such conditions, the temporal and spatial changes in the soil moisture during the growing season of crops depend on root characteristics and their distribution in the soil profile.

The ability of plants to obtain water and mineral nutrients from the soil is related to their capacity to develop their root systems. Gan et al. (2011) suggested that a crop's root system can compensate by increasing or relocating maximal root growth to higher soil moisture regions, helping maintain plant growth under dry soil conditions (Rendig \& Taylor, 1989). Jalota et al. (1980) observed more root growth of wheat with higher moisture content in the soil profile at seeding. The root length density of crops during the dry season tends to decrease mid-season at shallow soil depths, whereas it continues to increase throughout the growing season at deeper soil depths (Moroke et al., 2005). These changes parallel the trend in maximum soil moisture depletion from successively deeper layers as the season progresses.

Understanding soil moisture depletion by crops during the growing season and its residual level in the soil profile at crop harvest can help choose appropriate subsequent crops. To enhance the sustainability of dryland cropping systems, the sequence of crops is arranged to grow low water-using crops followed by high water-using crops so that excess soil water unused by the previous crop is available to the next crop (Unger et al., 2006; Lenssen et al., 2014). Stratified soil moisture depletion in crop rotations may improve the overall water use efficiency (Bunting \& Kassam, 1988; Gregory, 1989; Roder et al., 1989). Lenssen et al. (2014, 2018) and Schlegel et al. (2017) found greater soil water storage and water use efficiency with diversified crop rotations 
than monocropping. Schlegel et al. (2019) stated that crop rotations could efficiently use soil water and enhance dryland crop yields compared to monocropping.

There has been considerable research on the root growth and soil moisture changes for various crops under several climatic, agronomic and soil conditions. However, limited research is available on early-season root growth based on the influence of previous and current crops, and on pattern of soil moisture depletion during the growing season and its residual level for different crops under similar rainfed agriculture conditions that prevail in the study area. We hypothesized that a crop grown in the rotation might have better early-season root growth compared to the same crop grown under monoculture, because some negative factors associated with monoculture are alleviated. We also hypothesized that soil moisture content and depletion pattern during the growing season and residual soil moisture might be affected by crop type. Thus, the early-season root characteristics of crops and the depletion of soil moisture by the crops during the growing season were monitored in a field study.

\section{Materials and Methods}

\subsection{Site, Soil, and Weather}

The field experiment was located south of Donnelly in a field with the legal land location of NW7-77-20W5 (GPS: $55^{\circ} 39^{\prime} 38.43^{\prime \prime} \mathrm{N}, 117^{\circ} 6^{\prime} 10.64^{\prime \prime} \mathrm{W}$ ), southeast Peace Region, Alberta, Canada. The soil at the site was a clay loam Luvisol (Soil Classification Working Group 1998). The $0-15 \mathrm{~cm}$ soil depth had $48 \mathrm{~g} \mathrm{~kg}^{-1}$ organic matter, $6.1 \mathrm{pH}$ (water), and $16.4 \mathrm{cmol}(+) \mathrm{kg}^{-1}$ CEC. Spring soil moisture (SSM) and monthly precipitation during the growing season data were obtained from the weather station at Ballater in Alberta, located $5 \mathrm{~km}$ from the site (Table 1).

Table 1. Spring soil moisture (SSM), monthly precipitation total during crop growing seasons, and their 30 -yr average (Normal); from the Ballater weather station, Alberta, Canada

\begin{tabular}{lllll}
\hline & \multicolumn{4}{c}{ SSM and monthly precipitation total (mm) } \\
\cline { 2 - 5 } & 2013 & 2014 & 2015 & Normal \\
\hline SSM & 60.0 & 60.4 & 50.0 & 75.0 \\
May (121-151 Julian days) & 19.6 & 21.1 & 19.4 & 42.2 \\
June (152-181 Julian days) & 101.8 & 58.1 & 34.4 & 74.2 \\
July (182-212 Julian days) & 65.4 & 30.4 & 28.6 & 66.5 \\
Aug. (213-243 Julian days) & 13.6 & 2.6 & 44.5 & 55.8 \\
May to Aug. total & $\mathbf{2 0 0 . 4}$ & $\mathbf{1 1 2 . 2}$ & $\mathbf{1 2 6 . 9}$ & $\mathbf{2 3 7 . 7}$ \\
\hline
\end{tabular}

\subsection{Experimental Details}

A study on crop rotation was conducted from 2009 to 2015. A randomized complete block design was used to compare ten crop rotations that included canola, wheat, pea, barley, and flax, plus the monocultures of canola and wheat. The details on treatments, agronomic practices, and crop yield results have been presented by Gill (2018). The current research measured periodic soil moisture content during the 2013, 2014, and 2015 crop growing seasons and root growth in the early-season of 2015. The relevant procedures for these measurements are described below.

The crops were seeded on May 14, 21, and 11 in 2013, 2014, and 2015, which corresponded to the 134, 141, and 131 Julian day, respectively. All crops were harvested on Sept. 14 (257 Julian day) in 2013 and on Sept. 6 (249 Julian day) in 2014. In 2015, crop harvest occurred on Sept. 10 (253 Julian day, wheat and pea), Sept. 19 (262 Julian day, barley), Sept. 28 (271 Julian day, canola), and Oct. 8 (281 Julian day, flax).

For root measurements, selected treatments to compare the effects of 2014 canola and wheat (termed as previous crops) on the early-season root growth of canola (Brassica napus L.), wheat (Triticum aestivum L.), and flax (Linum usitatissimum L.) in 2015 (subsequent crops). Ten intact plants (shoots and roots) plus surrounding soil from representative areas of plots under wheat, canola, and flax crops were collected after 37 days of seeding, on June 17, 2015 (168 Julian day). The soil and roots were soaked in water for several hours. This was followed by gently shaking under water and repeated rinsing to remove the soil. The remaining debris was carefully picked off using tweezers. Then the shoots of five representative plants were cut so that all roots were still attached to the base. These representative plant's roots were spread in trays and scanned using a WinRHIZO Regular V.2013, XL Rhizo plus STD4800 scanner imaging machine (www.regentinstruments.com). WinRHIZO assigns root lengths to predefined diameter classes and counts the tips. Then the scanner provides estimates of the length, surface area and volume measurements for different diameter sized root classes, i.e., for the $0<0.5,0.5<1.0$, 
$1.0<1.5,1.5<2.0,2.0<2.5,2.5<3.0,3.0<3.5,3.5<4.0,4.0<4.5,>4.5 \mathrm{~mm}$ diameter roots. The roots and shoots of the five plants were dried to determine their dry masses. For presentation, data for roots of different sizes were grouped into thin $(<0.5 \mathrm{~mm})$, medium $(>0.5<1.5 \mathrm{~mm})$, and thick $(>1.5 \mathrm{~mm})$ categories (Tables 2 and 3). The data were subjected to the Paired T-test to determine the effect of previous wheat and canola crops on root and shoot measurements of canola, wheat, and flax crops. Differences were considered significant at $\mathrm{p}<$ 0.5 .

Soil moisture measurements were done for all the crops being grown in different treatments of experiment during the given growing season. Thus soil moisture could be monitored only under four crops (barley, canola, pea, and wheat) in 2013, two crops (canola and wheat) in 2014, and four crops (canola, flax, pea, and wheat) in 2015. Soil moisture was measured at depths of 0-10, 10-20, 20-30, and 30-40 cm under the wheat, canola, flax, barley (Hordeum vulgare L.), and pea (Pisum sativum L.). A profile probe (PR2-UM-3.0) and a moisture meter (HH2 version 4.0) of the Delta T Devices Ltd, 2008, 130 Low Road, Burwell, Cambridge, CB25 0EJ (www.delta-t.co.uk) were used to measure soil moisture at different depths. The profile probe has a sealed polycarbonate rod $(\sim 2.5 \mathrm{~cm}$ diameter) with paired stainless steel electronic sensors at fixed intervals along its length. When power is applied, each pair of sensors generates a simple analog DC voltage $(100 \mathrm{MHz})$ that transmits an electromagnetic field extending about $10 \mathrm{~cm}$ in the soil. The moisture meter was used to apply power to the profile probe sensors, measure the output signal voltage returned, and convert it to soil moisture units (volumetric) using a linearization table and soil-specific parameters. The signal's strength is related to the permittivity of soil, predominantly dependent on water $(\approx 81$ permittivity compared to $\approx 4$ for soil and $\approx 1$ for air). Specified fiberglass access tubes $(2.5 \mathrm{~cm}$ diameter $)$ were installed at the start of each growing season to insert the profile probe for readings at different soil depths. The soil moisture values and standard deviations for the $0-20 \mathrm{~cm}$ (average for the $0-10$ and $10-20 \mathrm{~cm}$ ) and $20-40 \mathrm{~cm}$ (average for the 20-30 and 30-40 cm) depths are presented in Figures 1, 2, and 3.

\section{Results}

\subsection{Early-Season Root Growth}

\subsubsection{Previous Crop Effects}

The total length, surface area, volume, and number of tips for canola roots showed significantly greater values on wheat than on canola stubble (Table 2). Similarly, the values for the thin, medium, and thick canola roots were also significantly greater on wheat than on canola stubble; except for the length, surface area, and volume of thick roots and the number of tips for the medium roots. Flax roots length, surface area, volume, and the number of tips also tended to be greater on wheat than on canola stubble, both for the different sizes and total values, but the differences were not statistically significant. Unlike the canola and flax roots, the wheat roots length, surface area, volume, and the number of tips for the thin, medium, and thick roots and their total values were not consistently influenced by the previous crops of canola and wheat.

The root and shoot masses of canola and flax tended to be greater on the wheat than on the canola stubble, with significant differences for the shoot mass of canola (Table 3 ). The stubble type did not influence the root and shoot masses of wheat. 
Table 2. Early-season length, surface area, volume, and the number of tips for the thin $(<0.5 \mathrm{~mm})$, medium $(>0.5$ $<1.5 \mathrm{~mm}$ ), and thick (>1.5 mm) roots (for five plants) of canola, wheat, and flax in 2015, as influenced by the previous crops of canola and wheat in a field study, Alberta, Canada

\begin{tabular}{|c|c|c|c|c|c|c|c|c|c|}
\hline \multirow{2}{*}{ Roots size } & \multicolumn{3}{|c|}{ Canola } & \multicolumn{3}{|c|}{ Wheat } & \multicolumn{3}{|c|}{ Flax } \\
\hline & Canola & Wheat & $\mathrm{Std}^{\mathrm{a}}$ & Canola & Wheat & $\mathrm{Std}^{\mathrm{a}}$ & Canola & Wheat & $\mathrm{Std}^{\mathrm{a}}$ \\
\hline \multicolumn{10}{|l|}{ Length, $\mathrm{mm}$} \\
\hline Thin & 405 & 653 & $71.4^{*}$ & 765 & 807 & $217^{\mathrm{NS}}$ & 650 & 758 & $290^{\mathrm{NS}}$ \\
\hline Medium & 57.2 & 101.7 & $26.2^{*}$ & 176 & 162 & $50.8^{\mathrm{NS}}$ & 69.8 & 107.6 & $42.3^{\mathrm{NS}}$ \\
\hline Thick & 33.3 & 39.1 & $8.6^{\mathrm{NS}}$ & 36.1 & 34.5 & $15.0^{\mathrm{NS}}$ & 6.14 & 11.22 & $5.00^{\mathrm{NS}}$ \\
\hline Total & 495 & 794 & 94.1* & 977 & 1004 & $275^{\mathrm{N} \bar{S}^{-}}$ & 730 & 883 & $337^{\mathrm{NS}}$ \\
\hline \multicolumn{10}{|c|}{ Surface area, $\mathrm{cm}^{2}$} \\
\hline Thin & 21.3 & 35.0 & $4.2 *$ & 55.8 & 58.8 & $14.3^{\mathrm{NS}}$ & 47.85 & 58.39 & $25.8^{\mathrm{NS}}$ \\
\hline Medium & 18.3 & 30.7 & $4.7^{*}$ & 41.2 & 37.8 & $13.2^{\mathrm{NS}}$ & 16.27 & 24.19 & $8.40^{\mathrm{NS}}$ \\
\hline Thick & 29.3 & 41.3 & $11.0^{\mathrm{NS}}$ & 36.2 & 33.5 & $13.3^{\mathrm{NS}}$ & 6.14 & 11.22 & $5.00^{\mathrm{NS}}$ \\
\hline Total & 68.9 & 107.3 & $11.9^{*}$ & 133.2 & 130.1 & $38.2^{\mathrm{NS}}$ & 80.1 & 107.0 & $42.8^{\mathrm{NS}}$ \\
\hline \multicolumn{10}{|c|}{ Volume, $\mathrm{cm}^{3}$} \\
\hline Thin & 0.125 & 0.209 & $0.032 *$ & 0.391 & 0.412 & $0.100^{\mathrm{NS}}$ & 0.327 & 0.419 & $0.202^{\mathrm{NS}}$ \\
\hline Medium & 0.298 & 0.500 & $0.075^{*}$ & 0.848 & 0.769 & $0.300^{\mathrm{NS}}$ & 0.337 & 0.480 & $0.141^{\mathrm{NS}}$ \\
\hline Thick & 2.284 & 4.119 & $1.17^{\mathrm{NS}}$ & 3.633 & 3.386 & $1.229^{\mathrm{NS}}$ & 0.293 & 0.609 & $0.300^{\mathrm{NS}}$ \\
\hline Total & 2.71 & 4.83 & $1.16 \%$ & 4.872 & 4.567 & $1.577^{\mathrm{N} \overline{\mathrm{S}}}$ & 0.700 & 1.034 & $0.400 \mathrm{NS}$ \\
\hline \multicolumn{10}{|c|}{ Number of tips } \\
\hline Thin & 1931 & 3132 & $701 *$ & 1885 & 1725 & $603^{\mathrm{NS}}$ & 1242 & 1378 & $243^{\mathrm{NS}}$ \\
\hline Medium & 12.8 & 19.8 & $8.4^{\mathrm{NS}}$ & 46.2 & 41.3 & $8.9^{\mathrm{NS}}$ & 13.75 & 26.25 & $4.20^{\mathrm{NS}}$ \\
\hline Thick & 4.75 & 3.50 & $1.00 *$ & 4.25 & 5.33 & $3.40^{\mathrm{NS}}$ & 4.25 & 4.50 & $1.30^{*}$ \\
\hline Total & 1949 & 3156 & $702 *$ & 1936 & 1772 & $614^{\mathrm{NS}}$ & 1260 & 1409 & $244^{\mathrm{NS}}$ \\
\hline
\end{tabular}

Note. ${ }^{\mathrm{a}}$ The ${ }^{\mathrm{NS}}$ and $*$ refers to the effects of previous crop being not significant and significant at the $\mathrm{p}<0.5$, respectively.

Table 3. Dry masses of roots and shoots (for five plants) of canola, wheat, and flax as influenced by the previous crops of canola and wheat

\begin{tabular}{|c|c|c|c|c|c|c|c|c|c|}
\hline \multirow{2}{*}{ Mass (g/5 plants) } & \multicolumn{3}{|c|}{ Canola } & \multicolumn{3}{|c|}{ Wheat } & \multicolumn{3}{|c|}{ Flax } \\
\hline & Canola & Wheat & $\mathrm{Std}^{\mathrm{a}}$ & Canola & Wheat & $\mathrm{Std}^{\mathrm{a}}$ & Canola & Wheat & $\mathrm{Std}^{\mathrm{a}}$ \\
\hline Roots & 0.368 & 0.484 & $0.159^{\mathrm{NS}}$ & 0.409 & 0.414 & $0.098^{\mathrm{NS}}$ & 0.099 & 0.162 & $0.060^{*}$ \\
\hline Shoots & 2.560 & 3.610 & $0.624 *$ & 1.447 & 1.430 & $0.415^{\mathrm{NS}}$ & 0.354 & 0.514 & $0.228^{\mathrm{NS}}$ \\
\hline
\end{tabular}

Note. ${ }^{\mathrm{a}}$ The ${ }^{\mathrm{NS}}$ and * refers to the effect of previous crop being not significant and significant at the $\mathrm{p}<0.5$, respectively.

\subsubsection{Root Size Distribution of Crops}

Thin roots comprised 78 to $87 \%$ of the total root length of the canola, wheat, and flax, with much lower values for the medium (9.6 to 18.0\%) and thick (0.8 to 6.7\%) roots (Table 2). Almost all the tips (97 to $99 \%$ ) for the canola, wheat, and flax roots were on the thin roots. The thin roots also had the highest surface area for the wheat $(42-45 \%)$ and flax $(55-60 \%)$ crops, followed by medium and thick roots in decreasing order. In contrast, the canola root's surface area was highest for the thick (34.1-38.6\%) and lowest for the medium (26.6-28.7\%). Unlike the length, surface area, and number of tips, the thick canola and wheat roots had the highest volume, followed by the medium and thin roots in decreasing order. The flax roots volume values were evenly distributed in the thin, medium, and thick classes.

\subsection{Soil Moisture Content and Depletion Under Different Crops}

Under dryland agriculture practiced in the study area, crops are sown in May and harvested during the fall, followed by a cold winter with no crop until sowing during the following May. Stored soil moisture plus rain and depletion of soil moisture during the growing season provide water for crops. Rain and snow during winter 
increase the moisture content of the soil. With rare exceptions, soil moisture depletion occurs during the growing period of crops. Crop yield suffers in years with low rainfall, when soil moisture content drops to a low level and the crops cannot extract water.

\subsubsection{Season}

The season started with $75 \%$ of the average spring soil moisture (SSM) and received $84 \%$ of the average rainfall during the growing season (Table 1). For the crops seeded on 134 Julian day, the first measurement on 157 Julian day showed that the barley plots had slightly less soil moisture in the $0-20 \mathrm{~cm}$ soil than the plots under other crops (Figure 1a). The earlier growth of barley roots compared to other crops may have depleted the soil moisture. Between the 157 and 172 Julian days, soil moisture was depleted under barley but not under other crops, further increasing soil moisture differences under barley and other crops. Greater than average rain (Table 1) increased soil moisture content under all the crops on the 179 Julian day compared to the 172 Julian day. After the 179 Julian day, rapid soil moisture depletion was noticed until the 193 Julian day under barley and until the 199 Julian day under the other crops. From the 199 Julian day until the last measurement on the 246 Julian day (near harvest of crops), minimal soil moisture depletion was noticed under all the crops. During most of the growing season, the soil moisture content was lower under barley than the other crops. Amongst the canola, pea, and wheat crops, the differences in soil moisture content and depletion at the various measurement times were small and not consistent.

For the 20-40 cm depth, the soil moisture content between the 157 and 179 Julian day increased (Figure 1b), likely a result of little water use by the crops from this soil layer and above average rain during this period (Table 1). Between the 179 and 193 Julian days, some soil moisture depletion was observed with no apparent differences in soil moisture content under the different crops. Following the 193 Julian day, depletion of soil moisture content followed different trends for the crops. Under pea, depletion in the soil moisture content was faster than other crops between the 193 and 221 Julian days, and very little change occurred after the 221 Julian day. Under canola, a steady depletion of soil moisture was observed from 193 to 246 Julian days. Like canola, a steady but slightly lesser depletion of the soil moisture content was observed between the 193 and 246 Julian days under wheat. The lowest depletion rate in soil moisture during the 193 to 246 Julian day period was observed under barley compared to other crops. Thus higher soil moisture content was under the barley than other crops on the 207 to 246 Julian day measurements. 

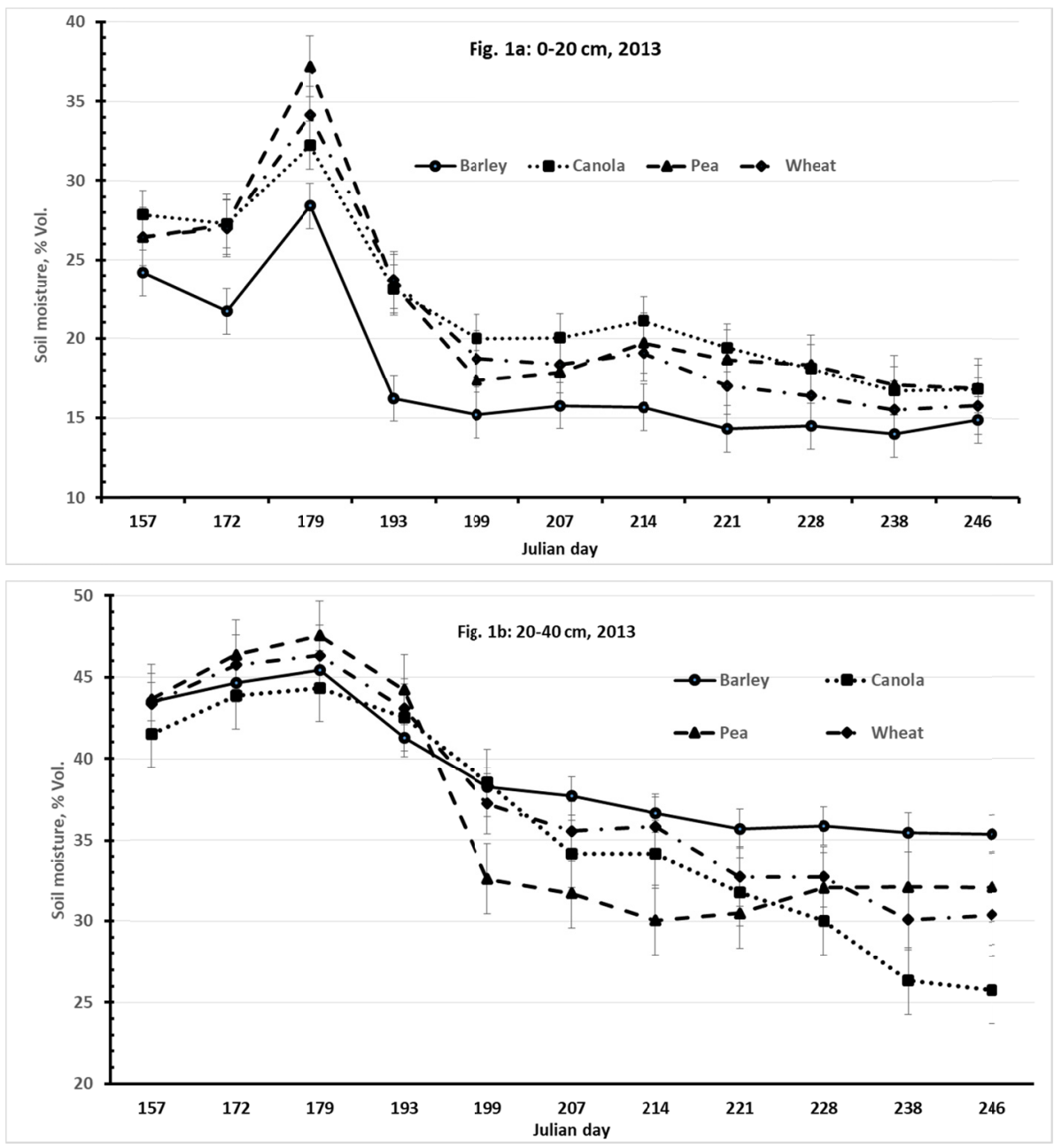

Figure 1. Soil moisture content in the $0-20$ and $20-40 \mathrm{~cm}$ layers under the barley, canola, pea, and wheat crops at different Julian days during 2013 in a field study, Alberta, Canada

As a result of the different temporal trends of soil moisture depletion from the $20-40 \mathrm{~cm}$ soil under the various crops, their rankings in soil moisture content during the measurements period changed as the growing season progressed. Soil moisture content was higher under the barley than other crops from the 207 to 246 Julian days, apparently due to lower depletion from this soil layer by barley compared to other crops. Comparison between the other crops showed that the lowest level of soil moisture content was under pea at the 199, 207, and 214 Julian days and under canola from the 228 Julian day onward. Soil moisture content was lower under canola than wheat on the 207, 214, and 221 Julian days, while the opposite was observed on the 238 and 246 Julian days. Similarly, soil moisture content was lower under pea than canola on the 199, 207, 214, and 221 Julian days, and the opposite was observed on the 228, 238, and 246 Julian days.

The 2013 results indicated that barley depleted soil moisture to a lower level than the other crops from the $0-20$ $\mathrm{cm}$ soil. From the $20-40 \mathrm{~cm}$ soil, barley depleted less soil moisture than other crops, and canola depleted soil moisture to a lower level than other crops.

\subsubsection{Season}

The growing season started with $81 \%$ of the normal SSM but had only $47 \%$ of the normal precipitation in the growing season with lower than the normal amount received each month (Table 1).

Between the 142 to 155 Julian days, rain (Table 1) and very little water use during emergence and early growth of the crops seeded on the 141 Julian day increased soil moisture content in the $0-20 \mathrm{~cm}$ soil (Figure 2a). A decline in soil moisture content started earlier under wheat (from 155 Julian day) than under canola (from 167 Julian day). Soil moisture depletion continued until the 189 Julian day under both crops. Compared to canola, the depletion of soil moisture content under wheat was faster until the 175 Julian day and slower between 175 and 
189 Julian days. By the 189 Julian day, a similar level of soil moisture content was reached under both crops and did not change much after that, probably due to the inability to extract water from dry soil. So both crops depleted soil moisture content to a similar level or utilized equal amounts of soil water from the $0-20 \mathrm{~cm}$ depth.

For the $20-40 \mathrm{~cm}$ soil in 2014 , a slight increase in soil water content was noticed under both crops in the initial stages (Figure $2 b$ ), due to the reasons described for the 0-20 soil. Like the 0-20 soil, the decline in soil moisture content started earlier under wheat (from 167 Julian day) than under canola (from 175 Julian day). A higher rate of soil moisture depletion occurred under both crops until the 189 Julian day, with a much slower change after that. From the 167 to 230 Julian day, the soil moisture content was lower under wheat than canola.

The 2014 results indicated an earlier start of soil moisture use by wheat than canola. The better capability of wheat than canola to use soil moisture from the $20-40 \mathrm{~cm}$ soil was not consistent with the 2013 results.

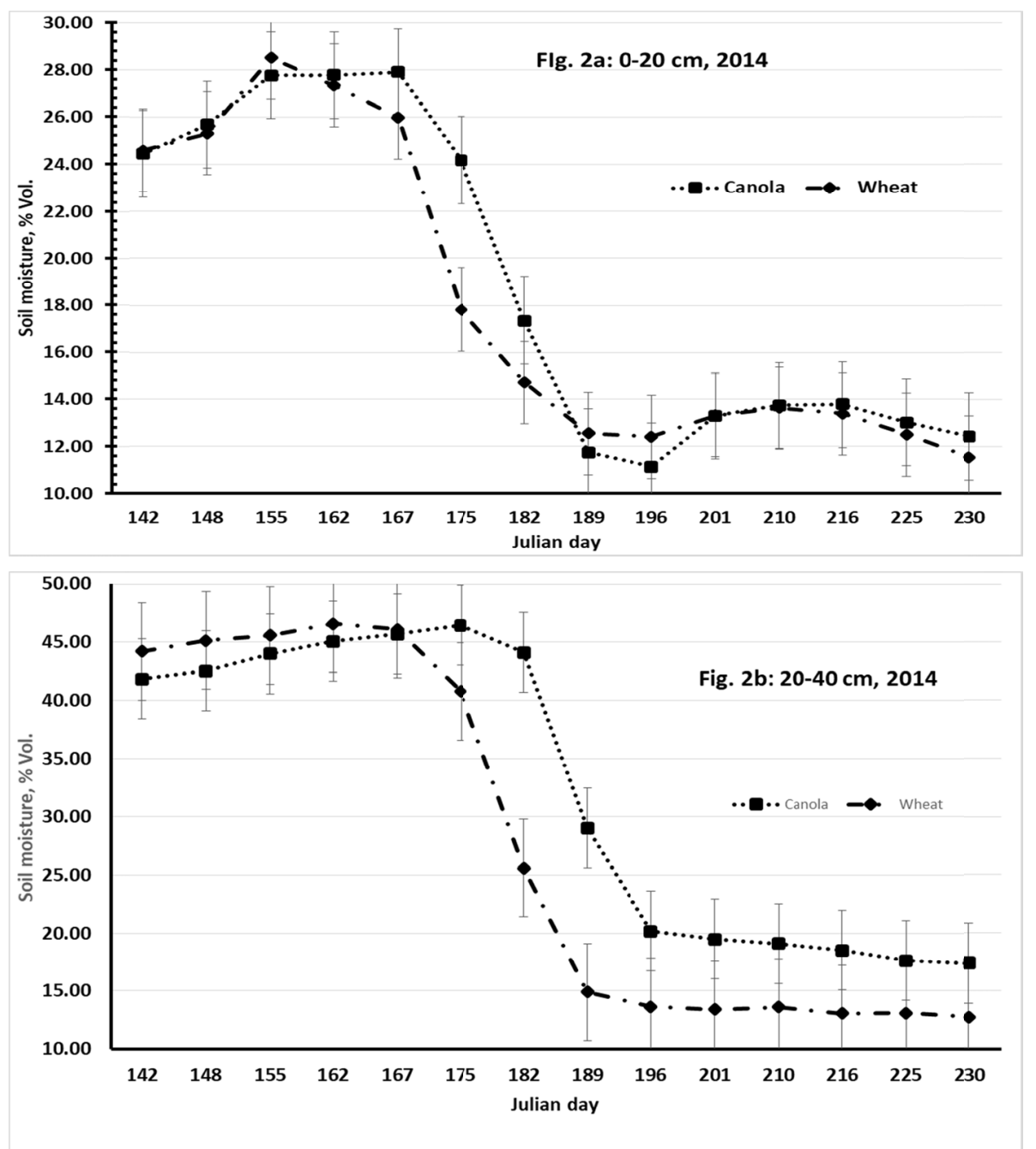

Figure 2. Soil moisture content in the 0-20 and 20-40 cm layers under the canola and wheat crops at different Julian days during 2014 in a field study, Alberta, Canada

\subsubsection{Season}

Only $68 \%$ of the normal SSM was observed at the start of the season, and $53 \%$ of normal precipitation was received during the growing season (Table 1). Frequent small amounts of rain occurred during late July and early Aug. (observation based on daily rain events).

Soil moisture depletion from the $0-20 \mathrm{~cm}$ soil started after the 147 Julian day under wheat while it began after the 155 Julian day under the other crops (Figure 3a). Compared to other crops, the soil moisture depletion between the 155 and 194 Julian days was faster under wheat and slower under flax. Between the 194 and 225 
Julian days, slight soil moisture depletion continued under flax. However, a gain in soil moisture was noticed under the other crops, apparently due to frequent rain events during late July and early August. Soil moisture depletion occurred under all crops between the 225 and 232 Julian days.

From the 155 to 202 Julian day, the soil moisture content in the $0-20$ soil was lower under wheat than other crops (Figure 3a). On the opposite side, the soil moisture content was higher under flax than other crops at the 183, 194, and 202 Julian days. Between the 194 and 225 Julian days, the soil moisture content increased under canola, pea, and wheat crops, probably resulting from more rain than water utilization. However, the soil moisture content under flax continued to decline, apparently due to more water use by flax relative to rain during this period. This discrepancy between the flax and other crops was apparently due to the more extended growth period of flax than the other crops.

For the 20-40 cm soil, there was little or no depletion of soil moisture content until the 162 Julian day (Figure $3 b)$. After 162 Julian day, the soil moisture content depleted slowly and consistently under flax until the last observation on 232 Julian day. A noticeable observation on the soil moisture content in the 20-40 cm soil was its higher level under flax than other crops at the 183, 194, and 202 Julian days, indicating delayed growth of flax roots in this soil layer. Under the other crops, soil moisture declined rapidly between the 162 and 194 Julian days, followed by no depletion after that. After the 194 Julian day, the canola, pea, and wheat crops were either unable to extract water at that low soil moisture level or their water need was fulfilled by frequent rain during this period.
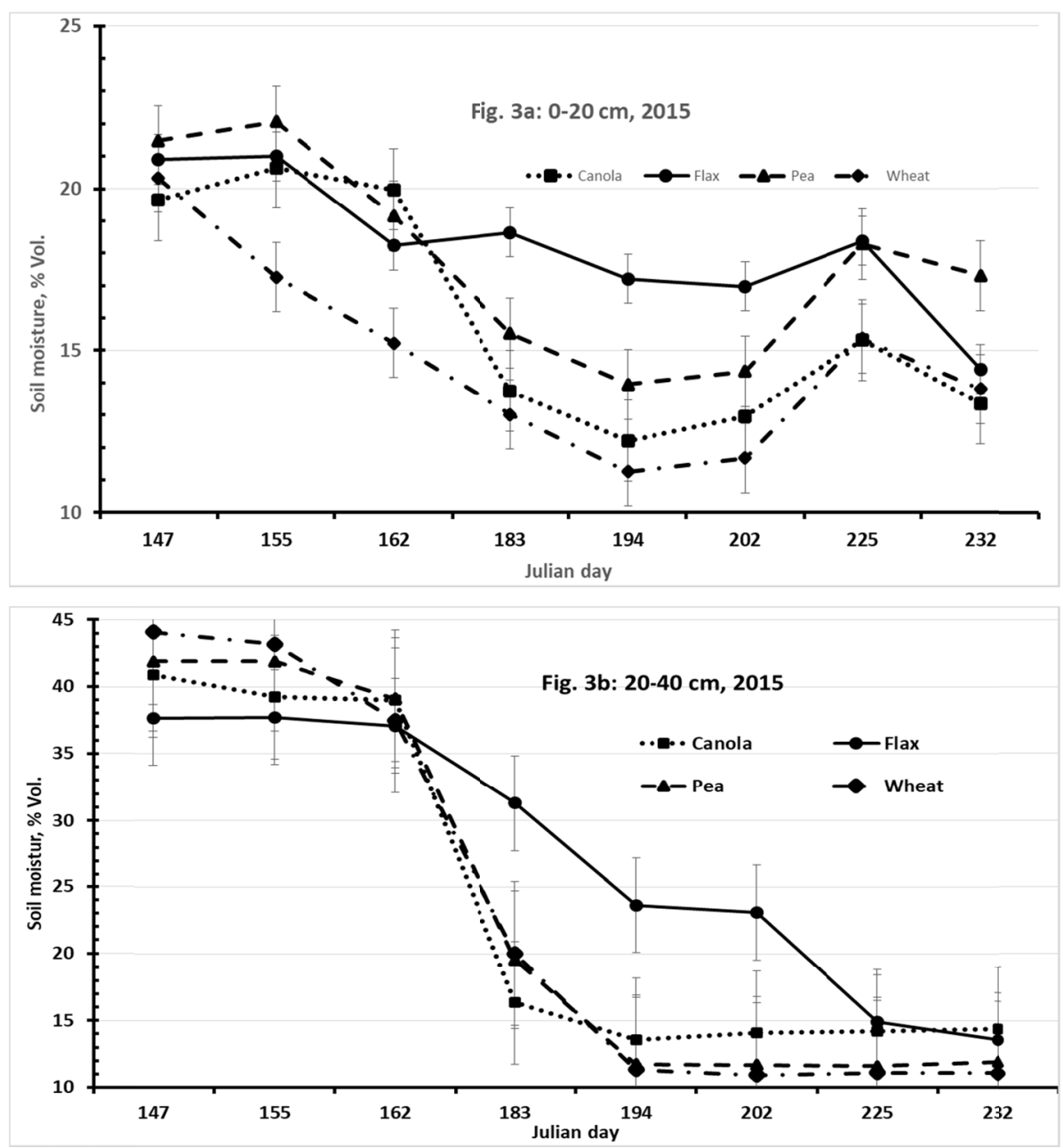

Figure 3. Soil moisture content in the 0-20 and 20-40 cm layers under the flax, canola, pea, and wheat crops at different Julian days during 2015 in a field study, Alberta, Canada 


\section{Discussion}

\subsection{Early-Season Root Growth}

The roots of a crop play vital role of linking the plant to soil and thereby soil to the atmosphere. Thus roots influence soil moisture and nutrient use efficiency by crops. Root growth is modified by soil factors such as temperature, fertility, aeration, and structure; and plant factors like vigor and ability of shoot to supply carbohydrates and other nutrients to developing roots. The root growth pattern may depend on the soil moisture content and depletion during the crop growing season (Ju et al., 2015).

Compared to canola stubble, the beneficial effects of wheat stubble on the early-season root and shoot growth of canola and flax (Tables 2 and 3) is supported by earlier research. Monreal et al. (2011) reported early-season arbuscular mycorrhizal fungi (AMF) colonization, lateral root area, and root biomass of flax to be greater when wheat rather than canola was the preceding crop. The establishment, early-season biomass, phosphorus accumulation, and seed yield of flax were greater on wheat than canola stubble (Grant et al., 2009). Grant et al. (2005) stated that spring wheat readily forms AMF association while canola does not, and the stubble and roots left by the wheat crop can create a favorable environment in the rhizosphere by increasing pore volume and nutrients for root proliferation of the subsequent crops.

The canola and flax root growth being better under the stubble of wheat than canola are supported by beneficial effects on canola yield from a 1 or 2 years break from canola in crop rotations (Gill, 2018). Similarly, Johnston et al. (2005) found that seeding canola two years in a row resulted in the lowest yield compared with canola in rotations, and O'Donovan et al. (2014) reported higher canola yield after a legume than after canola. Kutcher et al. (2013) speculated that lower canola yield on canola stubble might have been a reflection of less available soil $\mathrm{N}$ due to the increased demand from canola compared with other crops.

In other studies, the root vigor of crops was improved by rotations (Nickel et al., 1995), as were the root-related nutrient and water uptake functions (Copeland \& Crookston, 1992; Copeland et al., 1993). Cresswell and Kirkegaard (1995) observed that a canola crop did not improve a subsequent wheat crop's rooting depth. In contrast, Williams and Weil (2004) observed soybean (Glycine max L. Merr.) roots growing through compacted soil using channels made by roots of a previous canola crop. This suggests that a prior crop specie's benefit may depend on the following crop species and environmental conditions.

Similar early-season growth of wheat roots on the wheat and canola stubble in the present study indicates that some other crop rotation-related factors were preventing wheat stubble benefits. Gill (2018) reported the wheat yield on canola and wheat stubble was not consistently different. Evidence of more wheat root growth following maize (Zea mays L.) crop than rice (Oryza sativa L.) exists in literature (Sur et al., 1981). Other crop sequences research in western Canada indicates that more diverse rotations tend to have fewer pest problems and lower production risk than rotations based heavily on either cereal or broadleaf crops (Bailey et al., 2000; Johnston et al., 2005; Kutcher et al., 2011).

\subsection{Soil Moisture Content and Depletion}

Soil moisture data in 2013, 2014, and 2015 indicated an earlier start of soil moisture depletion by the cereals than other crops (Figures 1, 2, and 3). Compared to other crops, soil moisture depletion under flax started later and then continued slowly and steadily for a more extended period. Similar to our results, wheat used water faster than pulse and oilseed crops (Gan et al., 2008). It is not only the total root system that affects the soil water depletion, but the depth-wise distribution of roots also influences soil water depletion (Fan et al., 2016).

By end of the growing season, all crops depleted soil moisture down to about $15 \%$ or lower, except the $0-20 \mathrm{~cm}$ soil under pea in 2015; and the 20-40 cm soil under all crops in 2013 and under canola in 2014. Thus in most cases, there was almost an equal amount of residual soil moisture after different crops, indicating an only limited effect of crops under the study conditions. No depletion of soil moisture during later plant growth periods suggested a lack of available soil moisture, probably limited crop yield during the 2014 and 2015 seasons.

Similar to our results, the rate of root growth and water depletion was significantly faster under sunflower (Helianthus annuus) than sorghum (Sorghum bicolor), but sorghum reached maturity later in the growing season and water depletion was approximately the same for sunflower and sorghum (Moroke et al., 2005). They also observed that soil water depletion was significantly greater under sorghum than cowpea (Vigna unguiculata). Thus, the residual water content at the end of the growing season was greater under cowpea than under sorghum. Cowpea may exert a lower suction, hence lesser water uptake than sorghum and sunflower (Bunting \& Kassam, 1988). Comparisons of water depletion by Merrill et al. (2003) demonstrated more soil water content after dry 
pea than sunflower. However, the soil water gains following a pulse crop seemed to be partially offset by lower soil moisture gain during winter fallow.

Less soil moisture depletion from the $20-40 \mathrm{~cm}$ soil compared to the $0-20 \mathrm{~cm}$ soil during the initial period of crop growth and increase in the later season indicated the delayed establishment of roots in the deeper soil. Root systems of crops have the ability to increase or relocate maximal root growth to regions with greater water content in the soil profile, thereby maintaining plant growth under dry conditions (Rendig \& Taylor, 1989). Moroke et al. (2005) observed that the root length densities of sorghum and sunflower near the soil surface increased rapidly after planting but then declined, they increased throughout the growing season in deeper soil, and the soil water depletion corresponded to root length density of the crops. The root length density of crops during an extremely dry season tended to decrease during mid-season at shallow soil depths, whereas it continued to increase throughout the growing season at deeper soil depths (Moroke et al., 2005). Fan et al. (2016) stated that it is not only the total root system that affects the soil water depletion, but soil water depletion is according to the depth-wise distribution of roots. These statements support our result of more soil moisture depletion from deeper soil as the season progressed.

Different residual amounts of soil moisture after crops may have positive and negative aspects. Positively, more depletion capability means better water use efficiency and more rain infiltration, with less water runoff and soil erosion in years with adequate rain. Negatively, if the crop root zone soil is not fully charged before the start of the next crop, the subsequent crop can suffer from water stress (likely in dry areas).

\section{Conclusions}

Wheat stubble was beneficial compared to canola stubble in making the soil environment congenial to promote early-season root growth of the subsequent canola and flax crops. Similar growth of wheat roots in wheat and canola stubble indicated that some other monoculture-related factors were preventing the benefits of wheat stubble. About $80 \%$ of the total length for canola, wheat, and flax roots came from the thin roots. About $98 \%$ of the tips were on the thin roots. Root measurements data showed that an earlier crop could affect the early-season root growth of crops, and the effect may vary with the previous as well as the current crop type.

The 2013, 2014, and 2015 soil moisture depletion data indicated a relatively earlier start under barley and wheat and a delayed start under flax compared to canola and pea crops. The flax continued to deplete soil moisture for an extended period. With a few exceptions, all crops could deplete soil moisture to a similar level (down to about $15 \%$ or lower) by the end of the growing season. Thus, there was almost equal amount of residual soil moisture after the different crops and only a limited effect of the crops on the residual soil moisture content. The soil moisture availability probably limited crop production during the 2014 and 2015 seasons. Under the area's dryland agriculture conditions, the crop type could alter the soil moisture depletion pattern during the growing season, but had limited influence on the residual soil moisture at crop harvest. These findings indicated only limited influence of previous crops on the soil moisture availability for subsequent crops.

\section{Acknowledgements}

Thank you to the Alberta Canola Producers Commission, the Alberta Pulse Growers, the Alberta Barley Commission, the Government of Alberta (Agricultural Opportunity Fund), and the municipal governments of Smoky River, Big Lakes, Greenview, and Northern Sunrise for funding the project. All help from the SARDA Ag Research staff and directors is highly appreciated. L. Trudeau, AFSC, provided the SSM data. Thank you to Shelleen Gerbig (SARDA Ag Res), Dr. S. S. Malhi and Doug Penney for excellent suggestions and valuable input to the manuscript.

\section{References}

Bailey, K. L., Johnston, A. M., Kutcher, H. R., Gossen, B. D., \& Morrall, R. A. A. (2000). Managing crop losses from foliar diseases with fungicides, rotation, and tillage in the Saskatchewan Parkland. Can. J. Plant Sci., 80, 169-175. https://doi.org/10.4141/P99-069

Bunting, A. H., \& Kassam, A. H. (1988). Principles of crop water use, dry matter production, and dry matter partitioning that govern choices of crops and systems. In F. R. Bidinger \& C. Johansen (Eds.), Drought research priorities for dryland tropics (pp. 43-61). ICRISAT, Pantacheru, AP, India.

Copeland, P. J., \& Crookston, R. K. (1992). Crop sequence affects nutrient composition of corn and soybean grown under high fertility. Agron. J., 84, 503-509. https://doi.org/10.2134/agronj1992.000219620084 $00030028 \mathrm{x}$ 
Copeland, P. J., Allmaras, R. R., Crookston, R. K., \& Nelson, W. W. (1993). Corn-soybean rotation effects on soil water depletion. Agron. J., 85, 203-210. https://doi.org/10.2134/agronj1993.00021962008500020008x

Cresswell, H. P., \& Kirkegaard, J. A. (1995). Subsoil amelioration by plant roots-the process and the evidence. Aust. J. Soil Res., 33, 221-239. https://doi.org/10.1071/SR9950221

Fan, J., McConkey, B., Wang, H., \& Janzen, H. (2016). Root distribution by depth for temperate agricultural crops. Field Crop Research, 189, 68-74. https://doi.org/10.1016/j.fcr.2016.02.013

Gan, Y., Campbell, C. A., Liu, L., Basnyat, P., \& McDonald, C. L. (2008). Water use and distribution profile under pulse and oilseed crops in semiarid northern high latitude areas. Agricultural Water Management, 96, 337-348. https://doi.org/10.1016/j.agwat.2008.08.012

Gan, Y., Liu, L., Cutforth, H., Wang, X., \& Ford, G. (2011). Vertical distribution profiles and temporal growth patterns of roots in selected oilseeds, pulses and spring wheat. Crop and Pasture Sci., 62, 457-466. https://doi.org/10.1071/CP10406

Gill, K. S. (2018).Crop rotations compared with continuous canola and wheat for crop production and fertilizer use over 6 yr. Can. J. Plant Sci., 98, 1-11. https://doi.org/10.1139/cjps-2017-0292

Grant, C. A., Bittman, S., Monreal, M., Plenchete, C., \& Monreal, C. (2005). Soil and fertilizer phosphorus: effects on plant P supply and mycorrhizal development. Canadian J. Plant Sc., 85, 3-14. https://doi.org/ $10.4141 /$ P03-182

Grant, C. A., Monreal, M. A., Irvine, R. B., Mohr, R. M., McLaren, D. L., \& Khakbazan, M. (2009). Crop response to current and previous season applications of phosphorus as affected by crop sequence and tillage. Can. J. Soil Sci., 89, 49-66. https://doi.org/10.4141/CJPS07178

Gregory, P. J. (1989). Crop water use efficiency. In C. E. Whitman, J. F. Parr, R. I. Papendick, et al. (Eds.), Soil, water and crop/livestock management systems: Rainfed agriculture in the Near East Region (pp. 162-172). USAID, USDA, and ICARDA, Washington, DC.

Jalota, S. K., Prihar, S. S., Sandhu, B. S., \& Khera, K. L. (1980). Yield, water use and root distribution of wheat as affected by presowing and postsowing irrigation. Agricultural Water Management, 2, 289-297. https://doi.org/10.1016/0378-3774(80)90029-3

Johnston, A. M., Kutcher, H. R., \& Bailey, K. L. (2005). Impact of crop sequence decisions in the Saskatchewan Parkland. Can. J. Plant Sci., 85, 95-102. https://doi.org/10.4141/P04-090

Ju, C., Buresh, R. J., Wang, Z., Zhang, H., Liu, L., Yang, J., \& Zhang, J. (2015). Root and shoot traits for rice varieties with higher grain yield and higher nitrogen use efficiency at lower nitrogen rates application. Field Crop Research, 175, 47-55. https://doi.org/10.1016/j.fcr.2015.02.007

Kutcher, H. R., Brandt, S. A., Smith, E. G., Ulrich, D., Malhi, S. S., \& Johnston, A. M. (2013). Blackleg disease of canola mitigated by resistant cultivars and four-year crop rotations in western Canada. Can. J. Plant Pathol., 35, 209-221. https://doi.org/10.1080/07060661.2013.775600

Kutcher, H. R., Johnston, A. M., Bailey, K. L., \& Malhi, S. S. (2011). Managing crop losses from plant diseases with foliar fungicides, rotation and tillage on a Black Chernozem in Saskatchewan, Canada. Field Crops Res., 124, 205-212. https://doi.org/10.1016/j.fcr.2011.05.018

Lenssen, A. W., Sainju, U. M., Iversen, W. M., Allen, B. L., \& Evans, R. G. (2014). Diversification, tillage, and management influence spring wheat yield and water use. Agron. J., 106, 1445-1454. https://doi.org/ 10.2134/agronj14.0119

Lenssen, A. W., Sainju, U. M., Jabro, J. D., Allen, B. L., \& Stevens, W. B. (2018). Dryland pea productivity and soil water responses to tillage, crop rotation, and weed management practice. Agron. J., 110, 1843-1853. https://doi.org/10.2134/agronj2018.03.0182

Merrill, S. D., Tanaka, D. L., Krupinsky, J. M., \& Ries, R. E. (2003). Soil water depletion and coverage by residue under sunflower compared to other diverse crops. Proceedings of the 25th Sunflower research Workshop, Jan. 16-17, 2003, National Sunflower Association, Fargo, ND.

Monreal, M. A., Grant, C. A., Irvine, R. B., Mohr, R. M., McLaren, D. L., \& Khakbazan, M. (2011). Crop management effect on arbuscular mycorrhizae and root growth of flax. Can. J. Plant Sci., 91, 315-324. https://doi.org/10.4141/CJPS10136 
Moroke, T. S. (2002). Root distribution, water extraction patterns, and crop water use efficiency of selected dryland crops under differing tillage systems (Ph.D. Diss., Texas A\&M Univ., College Station, TX).

Moroke, T. S., Schwartz, R. C., Brown, K. W., \&. Juo, A. S. R. (2005). Soil water depletion and root distribution of three dryland crops. Soil Sci. Soc. Am. J., 69, 197-205. https://doi.org/10.2136/sssaj2005.0197

Nickel, S. E., Crookston, R. K., \& Russelle, M. P. (1995). Root growth and distribution are affected by corn-soybean cropping sequence. Agron. J., 87, 895-902. https://doi.org/10.2134/agronj1995.00021962008 $700050020 x$

O’Donovan, J. T., Grant, C. A., Blackshaw, R. E., Harker, K. N., Johnson, E. N., Gan, Y., ... Smith, E. G. (2014). Rotational effects of legumes and non-legumes on hybrid canola and malting barley. Agron. J., 106, 1921-1932. https://doi.org/10.2134/agronj14.0236

Rendig, V. V., \& Taylor, H. M. (1989). Principles of soil-plant interrelationships. McGraw-Hill Publ. Co., New York.

Roder, W., Mason, S. C., Clegg, M. D., \& Kniep, K. R. (1989). Yield-soil relationships in sorghum-soybean cropping systems with different fertilizer regimes. Agron. J., 81, 470-475. https://doi.org/10.2134/ agronj1989.00021962008100030015x

Schlegel, A. J., Assefa, Y., Haag, L. A., Thompson, C. R., Holman, J. D., \& Stone, L. R. (2017). Yield and soil water in three dryland wheat and grain sorghum rotations. Agron. J., 109, 227-238. https://doi.org/ 10.2134/agronj2016.07.0387

Schlegel, A. J., Assefa, Y., Haag, L. A., Thompson, C. R., Holman, J. D., \& Stone, L. R. (2019). Soil water and water use in long-term dryland crop rotations. Agron. J., 111, 1-10. https://doi.org/10.2134/ agronj2018.09.0623

Soil Classification Working Group. (1998). The Canadian system of soil classification. Agriculture and Agri-Food Canada (Publication 1646, Revised). National Research Council of Canada, Ottawa, ON.

Sur, H. S., Prihar, S. S., \& Jalota, S. K. (1981). Effect of rice-wheat and maize-wheat relation on water transmission and wheat root development on a sandy loam of the Punjab, India. Soil and Till. Res., 1, 361-371. https://doi.org/10.1016/0167-1987(80)90038-0

Unger, P. W., Payne, W. A., \& Peterson, G. A. (2006). Water conservation and efficient use. In G. A. Peterson, P. W. Unger, \& W. A. Payne (Eds.), Dryland Agriculture (2nd ed.). Agron. Monograph 23 (pp. 39-85). ASA, CSSA, and SSSA, Madison, WI. https://doi.org/10.2134/agronmonogr23.2ed.c3

Williams, S. M., \& Weil, R. R. (2004). Crop cover root channels may alleviate soil compaction effects on soybean crop. Soil Sci. Soc. Am. J., 68, 1403-1409. https://doi.org/10.2136/sssaj2004.1403

\section{Copyrights}

Copyright for this article is retained by the author(s), with first publication rights granted to the journal.

This is an open-access article distributed under the terms and conditions of the Creative Commons Attribution license (http://creativecommons.org/licenses/by/4.0/). 